\title{
Kinetic models of diagenesis in disturbed sediments. Part 1. Mass transfer properties and silica diagenesis
}

\author{
Jean-Pierre Vanderborght, Roland Wollast, and Gilles Billen ${ }^{1}$ \\ Laboratoire d'Environnement, Institut de Chimie Industrielle, Université Libre de Bruxellos, \\ Brussels, Belgium
}

\begin{abstract}
The results of chemical analysis of the interstitial water of several samples of sediments from a large muddy zone along the Belgian North Sea coast are reported. When special care is taken to collect the cores without disturbing the water-sediment interface, the vertical concentration profiles display typical patterns that cannot be explained by constant diffusivity models and suggest the existence of two distinct sedimentary layers with different mass transfer properties. A two-layer model is proposed to describe the vertical silica profiles. It assumes that the mass transfer coefficient in the first $3.5 \mathrm{~cm}$ of the sediment upper layer is 100 times higher than in the compacted lower layer. This large increase is mainly due to turbulent processes induced by the movement of the overlying water. From this model, the flux of dissolved silica across the water-sediment interface is calculated.
\end{abstract}

A knowledge of the properties of the water-sediment interface, as well as of the kinetics of the chemical reactions taking place in the sediments, is essential for describing and understanding the mass transfer processes between seawater and marine deposits. The boundary conditions at this interface are often poorly known; in some cases, its exact position is not even well defined, in large part because of the difficulty of collecting cores without disturbing the water-sediment interface. With the classical gravity or piston corer, and to a lesser extent the box corer, the turbulence caused by the instrument itself can resuspend the poorly compacted top sediments. Removal of the supernatant water of the core may carry away another fraction of the surfacc layer of the sediments. It is thus nccessary to use an adequate coring technique and to treat the cores with great care to avoid any loss of information.

The properties of the surface layer of the sediments generally differ considerably from those of the deeper layers, and may strongly affect the mass transport across the watcr-sediment interface. The degrce of compaction in the surface layer is low, especially in the case of muds. The flowing water perturbs this uncompacted layer and

\footnotetext{
${ }^{1}$ Research Fellow at the Fonds National de la Recherche Scientifique.
}

increases the mass transfer coefficient of dissolved species within the layer even if no resuspension occurs. The high porosity also favors an increased flux in the pore water of this layer. The biological activity of various benthic organisms is generally more intense in the surface layer and not only affects the chemistry of the environment but produces mechanical effects called bioturbation.

The upper sediments of the North Sea along the Belgian coast consist of organicrich muds (up to $5 \%$ organic $C$ ) deposited in shallow waters, at a mean depth of about $20 \mathrm{~m}$. High surface currents and frequent storms induce important shear stresses on the water-sediment interface, and favor the existence of a disturbed boundary layer. By contrast, the activity of the benthic macro- and meiofauna is extremely low in these sediments (De Coninck 1972). The existence of this layer has bcen demonstrated by careful coring techniques and close vertically spaced chemical analyses. The analytical results have been interpreted by kinetic models describing the vertical concentration profiles of various dissolved species in the pore water. Hore we give spccial attention to the influence of the disturbed layer on the vertical profiles and compute mass transfer coefficicnts through a kinetic model for dissolved silica. A comprchensive model for sulfate, nitrate, and 


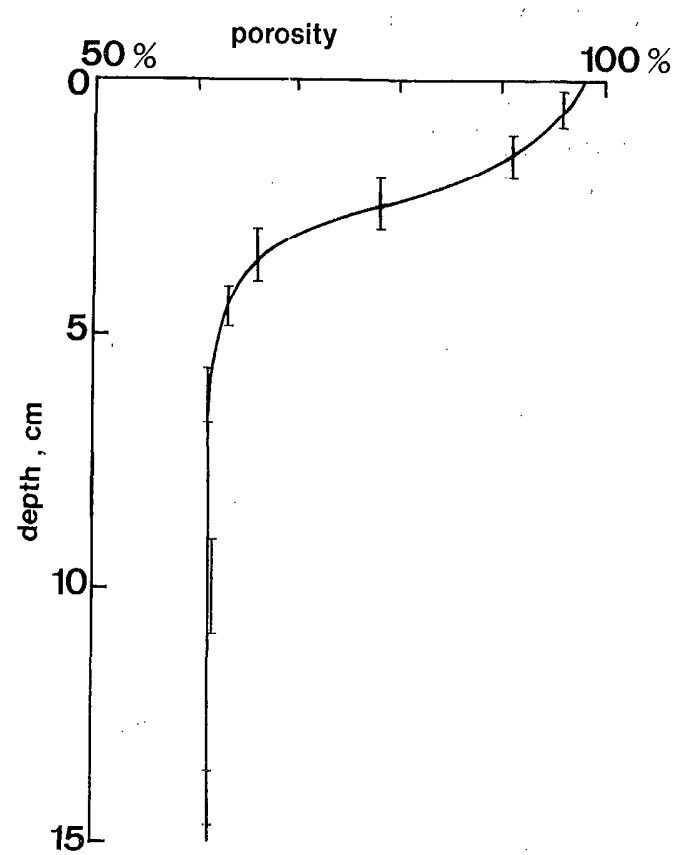

Fig. 1. Vertical profile of porosity of sediments of North Sea coastal region.

ammonia is given later (Vanderborght et al. 1977).

The results from cores taken at $51^{\circ} 19^{\prime} 45^{\prime \prime}$ N, $3^{\circ} 04^{\prime} 44^{\prime \prime} \mathrm{E}$ in March 1974 and April 1975 are reported here. These cores are represcntative of a large muddy zone along the Belgian and Dutch coasts and display the typical pattern of the disturbed upper layer. Sandy sediments, which can also be found in the same region, do not show this pattern. The results presented here may thus only be considered representative of the behavior of poorly consolidated sediments in shallow waters.

\section{Experimental}

The cores were collected by divers of the Belgian Navy with 6.35 -cm PVC core-liner tubes. The inner part of the tubes was covered with a thin polyethylene shield which allowed easy removal of the sediments from the core barrel. Penetration of the core-liner tube was restricted to the first $25 \mathrm{~cm}$. The tube was then sealed in situ with two rubber corks and brought aboard ship in a vertical position. Two cores were collected at each site. The first one was immediately treated by discarding the supernatant water and cutting the sediment in short segments $(1-4 \mathrm{~cm})$. These samples were centrifuged, the $\mathrm{Eh}, \mathrm{pH}$, and alkalinity of the interstitial water were measured, and the rest of the sample was deepfrozen for subsequent chemical analysis. The second core was immediately deepfrozen and later scgmented in the laboratory, where the fractions were centrifuged. Chemical analysis included determination of ammonia, nitrate, nitrite, silica, and sulfate. It is important to note that in the first procedure the upper $3 \mathrm{~cm}$ of the core can easily be lost if special precautions are not taken when the supernatant water is discarded.

\section{Results}

Porosity-The vertical profile of porosity is given in Fig. 1. The porosity decreases rapidly from $96 \%$ to about $65 \%$ in the first $4 \mathrm{~cm}$ and remains practically constant at greater depth. As a consequence of the high porosity of the upper part of the sediment, its physical consistency is quite fluid.

Redox potential-The existence of a sharp transition at a depth of $3.5 \mathrm{~cm}$ between a brown oxidized layer and a black reduced layer indicates that, in spite of the large amount of organic matter present, oxidizing conditions prevail in the upper part of the sediment. In this upper layer Eh values between $330 \mathrm{mV}$ and $230 \mathrm{mV}$ have becn measurcd; below $3.5 \mathrm{~cm}$, the $\mathrm{Eh}$ decreases rapidly to $-190 \mathrm{mV}$.

Dissolved silica-Figure 2 shows the vertical profile of dissolved silica from the core. A sharp gradient discontinuity can be seen at a depth of about $4 \mathrm{~cm}$, with a very low gradient in the upper part of the sediment. This profile differs from those usually described (Anikouchine 1967; Hurd 1973), where high gradients of dissolved silica are observed at the interface.

Sulfate-The classically described anaerobic reduction of sulfate can be observed in the deeper part of the North Sea 


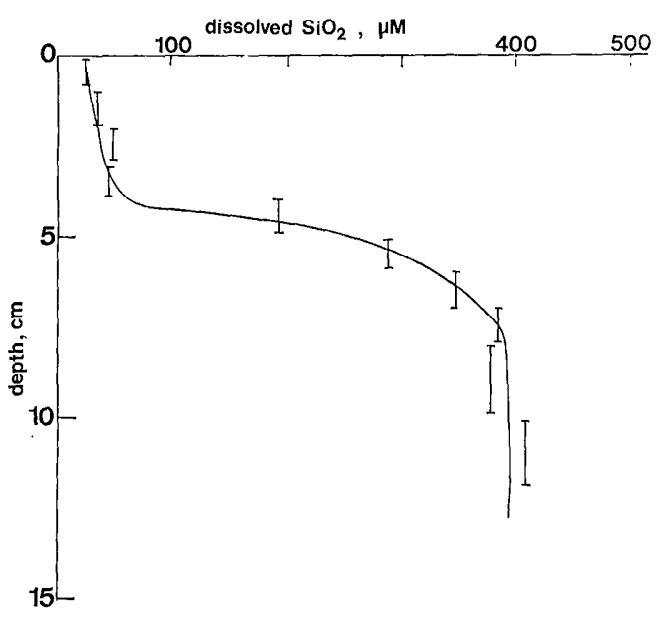

Fig. 2. Vertical profile of dissolved silica concentration in interstitial water.

sediments (Fig. 3) where sulfate is completely depleted at a depth of $25 \mathrm{~cm}$. As may be expected, sulfate is not reduced in the upper oxidizing layer.

Nitrate-Nitrate profiles from the cores show a maximum in the upper layer at a depth of about $2 \mathrm{~cm}$ (Fig. 4). This maximum can be related to the activity of autotrophic bacteria in the bulk of the sediments, which in turn strongly depends on the local redox potential (Vanderborght and Billen 1975). Such nitrification may occur in the upper layer of muddy sediments because of the prevailing oxidizing conditions.

Ammonia $-\Lambda \mathrm{n}$ increasc of the ammonia concentration in porc water, due to the decomposition of organic material, is also observed in the cores (Fig. 5). However, in contrast with the usual profiles obtained from deep-sea cores (Berner 1974), a sharp discontinuity of the concentration gradient occurs at a depth of about $4 \mathrm{~cm}$.

\section{Kinetic model for dissolved silica}

To quantitatively assess the importance of the upper layer of the sediments in the exchange with surface waters, we can tentatively describe the vertical concentration profile of dissolved silica by considering

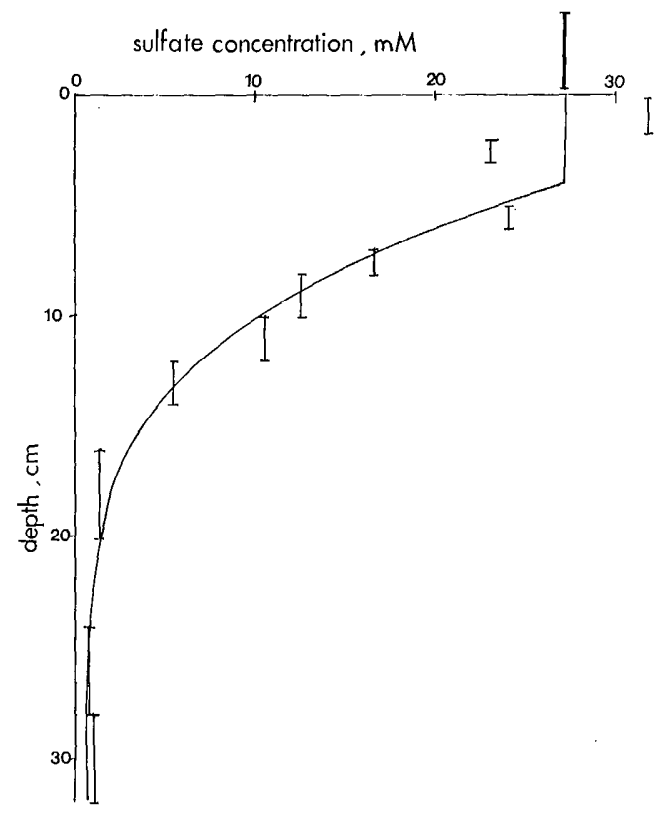

Fig. 3. Vertical profile of sulfate concentration in interstitial water.

the various physical and chemical processes taking place in the sediments. The general approach of the kinetic model has been extensively described by Berner (1971, 1974) for homogeneous sediments. However, models for homogeneous deposits are not able to account for the existence of discontinuities in the concentration gradient such as we observe in the profiles of the North Sea cores. These profiles strongly suggest that we can distinguish a thin disturbed layer near the water-sediment interface from a rather consolidated underlying sediment. The continuous decrease of porosity and mochanical perturbations with depth implies that the mass transfer coefficient is a continuous function of depth. However, a simplification of the mathematical treatment has been made by considering a two-layer sediment system, where each layer is characterized by a constant mass transfer coefficient. This approach has been used by Peng et al. (1974) for radon transfer in the surface ocean and applied by Hammond et al. (1975) for 


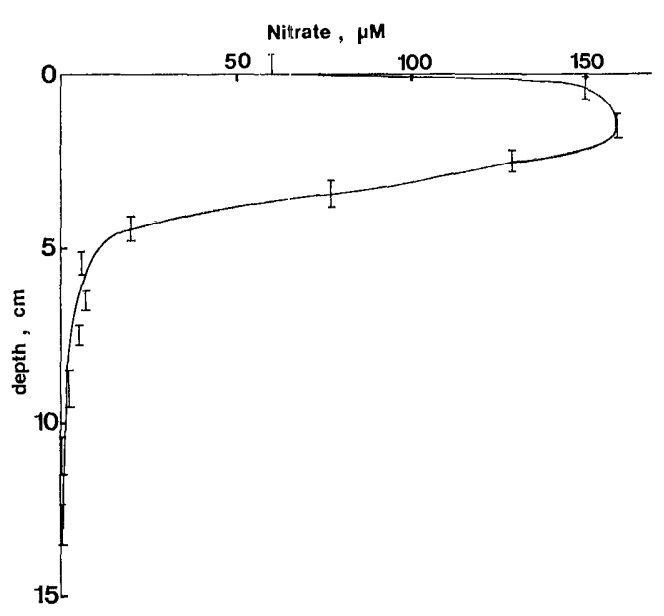

Fig. 4. Vertical profile of nitrate concentration in interstitial water.

predicting radon flux from estuarine sediments.

Furthermore, true steady state conditions do not occur in the North Sea, but it has been proven mathematically that after a variation in environmental conditions, a new steady state is nearly reached in the first $20 \mathrm{~cm}$ of the sediments within a few days (Vanderborght and Billen 1975). A stationary model will thus be considered here, implying that all the parameters appearing in the kinetic equation are timeindependent.

In the kinetic equation describing the vertical concentration profile of dissolved silica, the contribution of the following processes will be considered: diffusion in the pore water at a rate proportional to the concentration gradient; advection related to the deposition of fresh sediments; and chemical reactions affecting the concentration by silica production or consumption.

The net rate of dissolved silica production results from competition between dissolution of highly reactive opal and reprecipitation processes. The latter are not well understood, but it is generally admitted that, in the presence of clay minerals, reprecipitation of dissolved silica due to reactions with solids in the sedimentary column must be considered. It can be shown (Hurd 1973; Berner 1974; Fanning and

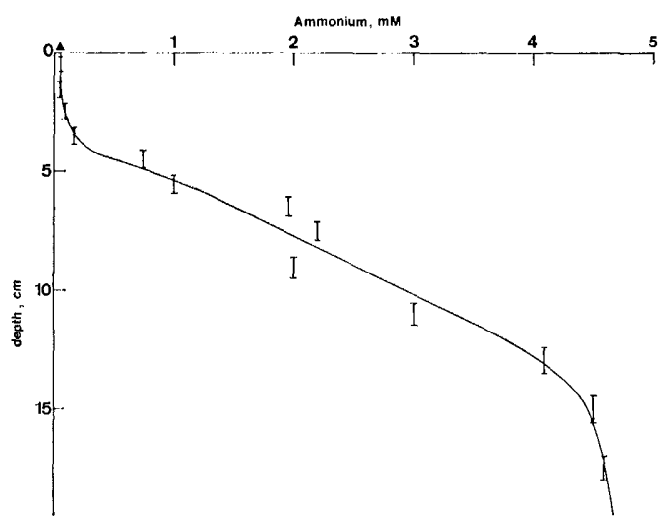

Fig. 5. Vertical profile of ammonium concentration in interstitial water.

Pilson 1974; Wollast 1974) that the global rate of reaction can be simply described by the kinetic relation

$$
r_{\mathrm{Si}}=k_{\mathrm{Si}}\left(\mathrm{Si}_{\infty}-\mathrm{Si}\right),
$$

where $k_{\mathrm{Si}}$ is an apparent kinetic constant, $\mathrm{Si}$ is the concentration of dissolved silica, and $\mathrm{Si}_{\infty}$ is either an equilibrium concentration or a steady state value of the dissolved silica concentration that is reached at depth. The equation describing the dissolved silica profile in the upper and lower layers can then be written

$$
D_{i} \frac{d^{2}(\mathrm{Si})}{d z^{2}}-\omega \frac{d(\mathrm{Si})}{d z}+k_{\mathrm{Si}}\left(\mathrm{Si}_{\infty}-\mathrm{Si}\right)=0
$$

where $D_{i}$ represents the mass transfer coefficient in the layer considered. The following boundary conditions are imposed to solve the system: at $z=0$, the concentration is equal to the concentration $\mathrm{Si}_{0}$ in the overlying seawater; at large $z$ values, the concentration tends toward a finite value; at the interface between the upper and lower layer $\left(z=z_{n}\right)$, the concentrations in each layer are equal and the flux across this interface is conservative:

$$
\begin{gathered}
\Phi_{n}=-\left.D_{1} \frac{d(\mathrm{Si})}{d z}\right|_{1}=-\left.D_{2} \frac{d(\mathrm{Si})}{d z}\right|_{2}, \\
\text { at } z=z_{n},
\end{gathered}
$$

where the subscripts 1 and 2 respectively 


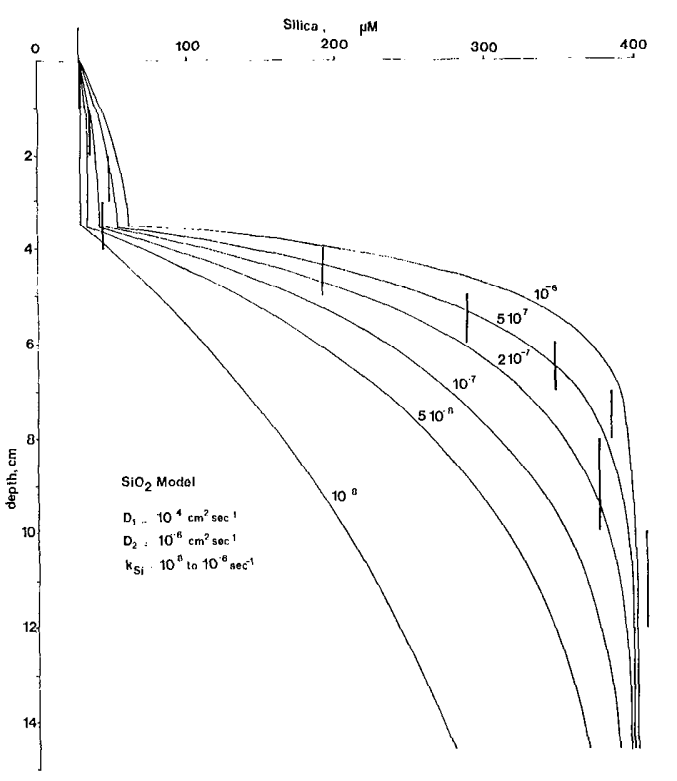

Fig. 6. Solution of diagenetic equation for a set of $k_{\mathrm{S} 1}$ values, compared with experimental profile of silica concentration in interstitial water.

refer to the upper and lower layer. The solution of Eq. 1 is, for the upper layer,

$$
\begin{aligned}
(\mathrm{Si})_{1}= & \mathrm{Si}_{\infty}-\left(\mathrm{Si}_{\infty}-\mathrm{Si}_{0}\right) \\
& \cosh \left[\alpha_{1}\left(z_{n}-z\right)\right] \\
& +\frac{+\beta \sinh \left[\alpha_{1}\left(z_{n}-z\right)\right]}{\cosh \left(\alpha_{1} z_{n}\right)} e^{\left(\omega / 2 D_{1}\right) z} \\
& +\beta \sinh \left(\alpha_{1} z_{n}\right)
\end{aligned}
$$

and for the lower layer,

$$
\begin{aligned}
(\mathrm{Si})_{2}= & \mathrm{Si}_{\infty}-\left(\mathrm{Si}_{\infty}-\mathrm{Si}_{0}\right) \\
& \cdot \frac{e^{\left(\omega / 2 D_{1}\right) z_{n}}}{\cosh \left(\alpha_{1} z_{n}\right)} e^{\left[\left(\omega / 2 D_{2}\right)-\alpha_{2}\right]\left(\approx-z_{n}\right)} \\
& +\beta \sinh \left(\alpha_{1} z_{n}\right)
\end{aligned}
$$

with

$$
\begin{aligned}
& \alpha_{1}=\left(\frac{\omega^{2}}{4 D_{1}^{2}}+\frac{k_{\mathrm{Si}}}{D_{1}}\right)^{\frac{1}{2}} \\
& \alpha_{2}=\left(\frac{\omega^{2}}{4 D_{2}^{2}}+\frac{k_{\mathrm{Si}}}{D_{2}}\right)^{\frac{1}{2}}
\end{aligned}
$$

and

$$
\beta=\frac{D_{2} \alpha_{2}}{D_{1} \alpha_{1}}
$$

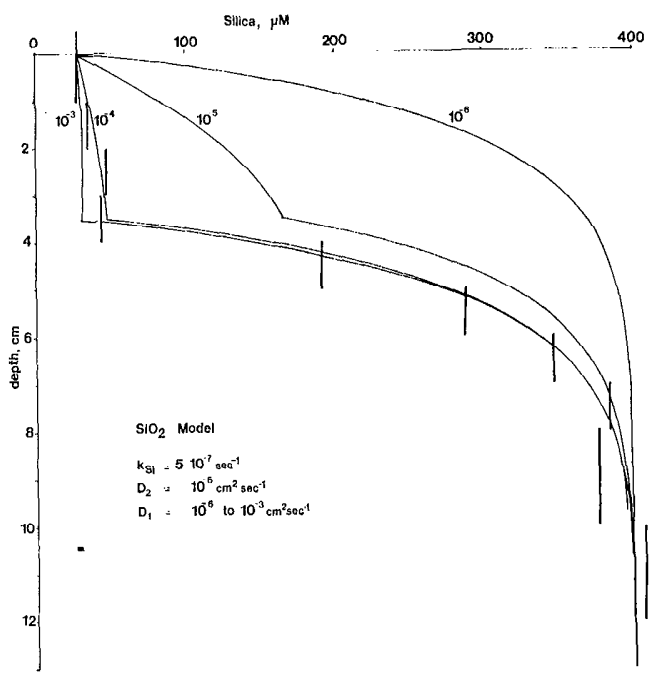

Fig. 7. Solution of diagenetic equation for a set of $D_{1}$ values, compared with experimental profile of silica concentration in interstitial water.

The depth $z_{n}$ is estimated from the porosity profiles; a value of $3.5 \mathrm{~cm}$, which also corresponds to the color transition in the cores, was used throughout the calculations. Many estimates have been made of the deposition rate $\omega$ for the southern part of the North Sea and a mean value of $3 \mathrm{~cm}$ per 100 years seems to be the best approximation (McCave 1973). Deposition rates one or two orders of magnitude higher can be locally observed.

The mass transfer for the lower part may be considered as due only to molecular diffusion. At the mean temperature of the system $\left(10^{\circ} \mathrm{C}\right)$, taking into account the porosity and an cstimation of the tortuosity of this layer, the whole sediment diffusion coefficient $D_{2}$ for the lower layer equals about $10^{-6} \mathrm{~cm}^{2} \mathrm{~s}^{-1}$ (Anikouchine 1967; Wollast and Garrels 1971; Hurd 1973; Berner 1974). The asymptotic value of the dissolved silica concentration $\mathrm{Si}_{\infty}$ can be deduced from the experimental profiles (Fig. 2): a value of $400 \mu \mathrm{M}$ has been selected. The only unknown parameters are $D_{1}$ and $k_{\mathrm{S} 1}$. A set of curves has been drawn for various values of $k_{\mathrm{Si}}$ (Fig. 6) and $D_{1}$ (Fig. 7). The distribution of dissolved silica in the lower part of the sediments is 


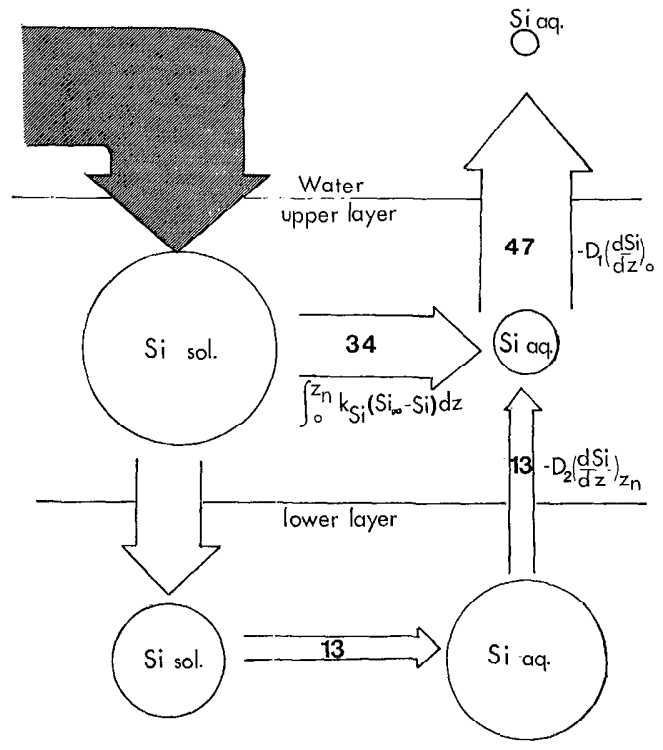

$\mathrm{mgSi} / \mathrm{m}^{2}$ day

Fig. 8. Schematic representation of transformation of silica in two-layer sediment and of fluxes across sediment-water interface and boundary between the two layers ( $\mathrm{Si}$ sol.—silica in solid phase; Si aq.--dissolved silica).

very sensitive to the values of $k_{\mathrm{Si}}$ (Fig. 6), which allows us to select the value $k_{\mathrm{Si}}=$ $5.0 \times 10^{-7} \mathrm{~s}^{-1}$. The best fit for the surface layer is then obtained for $D_{1}=10^{-4} \mathrm{~cm}^{2} \mathrm{~s}^{-1}$ (Fig. 7).

The value for $k_{\mathrm{Si}}$ is in agrecment with the value calculated from laboratory experiments by Grill and Richards (1964) on diatoms and by Hurd (1973) on radiolarians. The rate constants deduced from these experiments were, respectively, $2.0 \times$ $10^{-7}$ and $7.0 \times 10^{-7} \mathrm{~s}^{-1}$. The sedimentation rate $\omega$ can be neglected as long as it is $<10$ $\mathrm{cm}$ per year and does not need to be known with great precision. The value of the mass transfer coefficient $D_{1}$ for the upper layer is 100 times greater than the coefficient $D_{2}$ in the compacted layer. This large increase is partially due to the change of porosity and tortuosity (about a factor 2), but mainly to advective processes induced by the movement of the overlying water.
The model allows calculation of the flux across the boundary between layer 1 and 2:

$$
-D_{2}\left[\frac{d(\mathrm{Si})}{d z}\right]_{z_{n}} \text {. }
$$

as well as the flux across the water-sediment interface:

$$
-D_{1}\left[\frac{d(\mathrm{Si})}{d z}\right]_{0}
$$

and the net dissolution rate of silica in each layer (Fig. 8):

$$
\int_{0}^{z_{n}} k_{\mathrm{Si}}\left(\mathrm{Si}_{\infty}-\mathrm{Si}\right) d z
$$

and

$$
\int_{z_{n}}^{\infty} k_{\mathrm{Si}}\left(\mathrm{Si}_{\infty}-\mathrm{Si}\right) d z
$$

The contribution of the upper layer represents $70 \%$ of the total flux of silica out of the scdiments. As a consequence, the fluxes may be underestimated by a factor of four if this layer is discarded during sampling or handling of cores.

\section{References}

Anikouchine, W. A. 1967. Dissolved chemical substances in compacting marine sediments. J. Geophys. Res. 12: 505-509.

Benner, R. A. 1971. Principles of chemical sedimentology. McGraw-Hill.

- 1974. Kinetic model for the early diagenesis of nitrogen, sulfur, phosphorus and silicon in anoxic marine sediments, p. 427449. In E. D. Goldberg [ed.], The sea, v, 5. Wiley.

DE Coninck, L. 1972. Etude qualitative et quantitative du benthos. In Math. Model Sea, Rapp. Synth. 1. Comm. Polit. Sci.

Fanning, K. A., and M. E. Pilson. 1974. The diffusion of dissolved silica out of deep-sea sediments. J. Geophys. Res. 79: 1293-1297.

Grull, E. V., AND F. A. Richards. 1964. Nutrient regeneration from phytoplankton decomposing in sea water. J. Mar. Res. 22: 51-69.

Hammond, D. E., II. J. Srmpson, and G. MATHIEU. 1975. Methane and radon-222 as tracers for mechanisms of exchange across the sediment-water interface in the Hudson River Estuary. Am. Chem. Soc. Symp. Ser. 18, p. 119-132.

Hunw, D. C. 1973. Interaction of biogenic opal sediments and sea water in the central equa- 
torial Pacific. Geochim. Cosmochim. Acta 37: 2257-2282.

McCave, I. N. 1973. Mud in the North Sea, p: 75-100. In E. D. Goldberg [ed.], North Sea science. Mass. Inst. Technol.

Peng, T. H., T. Takatiashi, and W. S. Broecker. 1974. Surface radon measurements in the North Pacific station Papa. J. Geophys. Res 79: $1772-1780$.

Vanderborght, J. P., and G. Billen. 1975. Vertical distribution of nitrate concentration in interstitial water of marine sediments with nitrification and denitrification. Limnol. Oceanogr. 20: 953-961.
R. Wollast, and G. Billen. 1977. Kinetic models of diagenesis in disturbed "sediments. Part 2. Nitrogen diagenesis. Limnol. Oceanogr. 22: 794-803.

Wollast, R. 1974. The silica problem, p. 359392. In E. D. Goldberg [ed.], The sea, v. 5. Wiley. , and R. M. Gannels. 1971. Diffusion coefficient of silica in sea water. Nature 229: 94.

Submitted: 14 November 1975 Accepted: 24 January 1977 